\title{
Communicating Library Impact through the Assessment Website
}

\author{
Kristin Hall and Janet H. Clarke \\ Stony Brook University, USA
}

\section{Introduction}

Academic library assessment activities are designed to facilitate planning, improve programs and services, and demonstrate library impact on student academic success and faculty research productivity. One effective way to share assessment processes and outcomes is through scholarly publications in library and information sciences. However, presenting assessment activities on the library website is another essential way to share this impact activity with a wider audience, and especially with institutional and higher education stakeholders. With that in mind, how do academic libraries effectively communicate on their website their impact on the research and learning enterprise to their stakeholders? In accordance with ACRL's recommendations for demonstrating value and impact, what are best practices for demonstrating impact through the website, a far-reaching platform which gives libraries a unique opportunity for broadly communicating their alignment with institutional goals?

Stony Brook University is designing a mini-site as part of the overall libraries' web presence to share our assessment activities, findings, and statistics with our university community. Our goal is to create a web presence that demonstrates library impact on academic success in a way that is understandable to external stakeholders and to do so in a visually compelling way. As part of this project, a thorough review was conducted of the Association of American Universities (AAU) ${ }^{1}$ member institutions' library webpages to locate and study their assessment information to serve as a comparison. This examination revealed a lack of a library assessment presence on the majority of library websites. Where there was assessment information, some of it was difficult to follow because of library-centric presentation and lingo, and issues with organization, navigation, volume, scope, and types of materials presented. Using ACRL's Academic Library Impact: Improving Practice and Essential Areas to Research (Library Impact) ${ }^{2}$ and ACRL's The Value of Academic Libraries: A Comprehensive Research Review and Report (VAL Report) ${ }^{3}$ as a framework, the authors discussed the findings, deliberations, and recommendations for best practices in design, visual impact, and communication of assessment goals and processes with appropriate institutional contexts on a website.

\section{Assessment Trends and Priorities}

Demonstrating value has been an urgent priority for academic libraries. One of the most essential ways that libraries can do this is by aligning their work with their institutional missions. To that end, ACRL has identified specific areas of institutional missions that academic libraries can and do impact and should explore to further increase their value: student enrollment, retention, graduation rates; student success, achievement, learning, experience, engagement; faculty research productivity, grant proposals, grant funding, teaching; and institutional reputation and prestige. These research agenda areas should be used to shape or revise library missions, visions, and strategic directions in collections, services, and programming to ensure that academic libraries contribute maximum value to institutional outcomes. ${ }^{4}$

It follows that ACRL's agenda areas also help inform and shape library assessment planning and activities insofar as these assessment activities help libraries demonstrate their impact on institutional missions. Assessment helps libraries to be transparent and accountable, foster a culture of continuous evidence-based improvement and learning, and embrace change so they remain as a "centerpiece of their institutions." 5 Libraries have traditionally measured (and presented) internal library processes (input/output, service quality, user satisfaction). As these traditional measures "no longer resonate with many higher education stakeholders," there is a need to shift the paradigm of assessment to one that demonstrates the library's impact on learning and research outcomes. In this new paradigm, libraries must see themselves as an integral, active part of the learning and research enterprise of higher education, not just information repositories and physical spaces; librarians must focus on information skills, not just information access; and 
they must think like educators and research partners, not just service providers. The VAL Report shows that it is imperative that libraries improve their articulation of value to external stakeholders since they do not exist for themselves, but rather to advance institutional missions. In other words, academic libraries must reframe what they assess so they can demonstrate how they advance the mission of their institutions.

Building on the VAL Report's recommendations on targeted areas for program improvements and more effective communication of the library's contributions to institutional missions, and with input from key stakeholders, ACRL issued an update with priority research and action areas in its 2017 Impact Report:

- Communicate the library's contributions to the institution

- Match library assessment to institution's mission

- Include library data in institutional data collection

- Quantify the library's impact on student success

- Enhance teaching and learning

- Collaborate with educational stakeholders ${ }^{7}$

Communicating the library's impact to the institution requires libraries to present the library's contributions using terminology that is easily understandable by the institutional/higher education stakeholders, raise awareness of the library's participation in missional areas to those outside of the library, actively participate in campus and interdepartmental efforts, cultivate informal communication opportunities, and leverage the library's unique position of serving all students and majors. Matching library assessment to the institution's mission requires libraries to work with campus partners and departments to collaborate on common issues and goals, work with teaching and learning support services as well as faculty and students to build a culture of assessment, and align assessment activities to the institution's strategic directions. Including library data in institutional data collection requires libraries to have their data included in the systematic data collection processes and analyses of the institution to better connect the library with research, teaching, learning, and student success. Impact on student success has become the most significant way for institutions to demonstrate their value to their stakeholders, and libraries can quantify their impact in this area with data and assessment of library resources, programs, spaces, library instruction for student success, and other data points. Libraries must show the ways they contribute to critical thinking, student learning and engagement, and use spaces, collections, and programs to enhance learning and engagement. And libraries must collaborate with other partners and units on campus and at other institutions to improve student learning and success.

The Impact Report stressed that the first priority area-communicating the library's contribution to the institution-was indeed the most important, and that the other five areas support this priority area in more specific ways. ${ }^{8}$ Indeed, a library that is adequately achieving the other five priority areas, but is not communicating it effectively, through the website or otherwise, may still fail to demonstrate its value to its stakeholders. Lewin and Passonneau noted that "[i]nstitutions will not place high value on libraries if stakeholders cannot discern the positive impact library activities have on scholarship and teaching activities." Moreover, at least half of the ten "next steps" identified in the newly published white paper, Library Integration in Institutional Learning Analytics, ${ }^{10}$ involve communicating value or prioritizing user stories or impact narratives to further facilitate greater library integration with institutional data and analysis of student learning and success.

Given these guidelines, how can libraries utilize their websites to effectively communicate their value and impact? One way is to change their frame of reference away from the library to prioritize the perspective of the institution and other external stakeholders by presenting information that resonates with higher education goals. For example, we must consider what administrators may want to know when they visit our website: 
- What is the librarians' role in "high impact educational practices" such as first-year seminars, writing-intensive courses, undergraduate research, and capstone courses?

- How does the library's outreach and programming contribute to faculty and student engagement and cultivating an informed citizenry?

- How are liaison and/or first-year experience librarians interacting with first-year students to contribute to student retention?

- How is the library contributing to student recruitment, graduation rates?

Faculty and students will want to know:

- How much research time does the library save (reference transactions, research guides, database access) for my paper, research, or grant proposal?

- How is the library instruction contributing to student learning objectives?

- What general education requirements does the library help students meet?

Moreover, employers are looking for transferable skills in students:

- How does library instruction teach and reinforce critical thinking, analytical skills, problem-solving, locating, evaluating, and ethically using information from multiple sources?

Libraries can use these and other prompts from the VAL and Impact Reports to help reframe how they communicate the impact of their work in terms of student success and faculty productivity, rather than the traditional input/output framework.

Therefore, effectively communicating the library's value and impact on its website requires that the information and material:

- $\quad$ are outcomes-based, mission-focused;

- clearly resonate with institutional mission;

- align with other institutional reporting;

- communicate value and impact through evidence-based assessment practices, methods, and metrics;

- are easily understandable and appreciated by external stakeholders;

- $\quad$ are presented in the language of higher education;

- $\quad$ are open and accessible, not restricted by staff logins;

- explain the data, charts, and other metrics for what they show-do not make the reader have to do the work of making meaning of impact; and

- focus on the results of assessment (what will we do with it, how have we used it to improve library impact and value to institutional mission?), not on the assessment process itself.

So, being very intentional about framing what libraries communicate on their websites about their value and impact in the language of higher education is crucial. How they visually present this narrative through their website is just as important.

\section{Cognitive Load Theory and Visual Elements}

When learning new information, our working memory has a limited capacity in what it can process at one time. Research has found the average person can hold seven plus or minus two pieces of information in working memory at any one time. ${ }^{11}$ When there is too much information to process beyond what an individual's working memory can handle, they can experience a cognitive overload. ${ }^{2}$ "Cognitive load theory seeks to reduce or manage the working memory load, or cognitive load, in order to assist learners in developing meaningful learning experiences." ${ }^{\prime 3}$ 
According to Sweller, ${ }^{14}$ cognitive load can be broken down into intrinsic and extraneous components and is said to be additive in nature. Intrinsic cognitive load is the nature of the material being presented on the website. If the new information has many elements that must be processed or learned together such as interpreting Tableau data and charts, it is said to have a high element interactivity. This requires more working memory resources than learning unrelated single elements that do not interact together. Intrinsic cognitive load is usually fixed and can only be reduced by changing the nature of the learning task or by the act of learning itself. Sweller describes extraneous cognitive load as the way in which material is presented. When there is too much extraneous information (e.g., detailed reference transactions by hours), learners are using working memory for things other than learning and an unnecessary high cognitive load can result. This can be reduced by changing the way information is presented to the learner. ${ }^{15}$

As we focus on communicating library assessment, it is important for the designer/presenter to keep in mind working memory, the nature of the material being presented, and the way in which it is presented. Stephanie Evergreen reminds us that, "If our hard work is to draw attention, make an impact, and convince others to take action, then communication can no longer be presented in the weak style of the status quo." ${ }^{16}$ Schweppe and Rummer state that "a central recommendation for the design of multimedia learning materials is to take into account the limited capacity of working memory." 17 To reduce extraneous cognitive load, libraries can focus on the following visual elements to support efficient and effective processing of library information by external stakeholders. A summary is also provided in Table 1.

Dual Coding is presenting information using verbal and non-verbal codes or with words and pictures. This helps the viewer process and retain information more effectively. ${ }^{18}$ As Evergreen writes, "graphic elements can reduce the overload by doing some of the thinking for the reader."19 When the presenter uses meaningful words and appropriate images together, they are organizing and emphasizing information for the reader, freeing up working memory and helping them process and understand the presented information. Where appropriate, library assessment information should incorporate graphic elements or symbols to help facilitate meaning.

Organization of Material is organizing material in a way that is easy for the reader to understand to support retention. We naturally want to put things into categories. As a library, we want to present information so that external readers do not have to use working memory to organize the assessment information themselves. Reference icons are a good example of organizing information in a meaningful way. Evergreen describes reference icons "provide the reader with a mental organizational structure." ${ }^{20}$ Judgmental icons are another example which "quickly communicate our interpretation of our research findings." ${ }^{21}$ Reference and judgmental icons can also contain dual coding using verbal and non-verbal cues. ${ }^{22}$

Removing extraneous information that will hinder or reduce understanding in the presentation of assessment information is important. If there is too much information presented that is not absolutely needed to easily interpret findings and results, the reader is likely to experience cognitive overload and give up reviewing the information presented: we risk losing our audience.

Chunking is grouping single pieces of information into groups and is a technique for keeping information in working memory and eventually long-term memory. ${ }^{23}$ Phone numbers are a great example of chunking. Our brains view phone numbers as three grouped units of information instead of ten individual numbers. This technique helps to free up working memory so an individual can process more information at one time. Grouping related assessment items helps readers process and retain the information better. ${ }^{24}$

Drawing Attention is emphasizing to the viewer what we want them to know. We want to draw the viewer to the information that we deem most important or that has the most significance. Making this information stand out helps us communicate what value and impact they have over other information on the page. 
Table 1: Visual Elements to Help Reduce Extraneous Cognitive Load

\begin{tabular}{|c|c|c|}
\hline Visual Element & Example & Explanation \\
\hline Dual coding & Library Book & $\begin{array}{l}\text { Combining verbal and nonverbal elements; using words with } \\
\text { pictures }\end{array}$ \\
\hline $\begin{array}{l}\text { Organization of } \\
\text { material }\end{array}$ & $\underset{\text { Organize Content }}{\square}$ & $\begin{array}{l}\text { Providing a clear framework and organization of elements } \\
\text { that is orderly and easy to understand and follow. It is } \\
\text { important to keep in mind an external audience. Reference } \\
\text { and judgmental icons are good examples and can include dual } \\
\text { coding. }\end{array}$ \\
\hline $\begin{array}{l}\text { Remove extraneous } \\
\text { information }\end{array}$ & Remove & $\begin{array}{l}\text { Remove any information that is not essential to processing } \\
\text { and understanding the information you are presenting. This } \\
\text { will free up working memory to process the intrinsic nature } \\
\text { of the material. }\end{array}$ \\
\hline $\begin{array}{l}\text { Chunking } \\
\text { information }\end{array}$ & $\begin{array}{l}\frac{1}{2} \\
\frac{3}{3} \\
\frac{4}{5} \\
\frac{6}{6}\end{array} \rightarrow 2$ & $\begin{array}{l}\text { Grouping single pieces of information into groups. This frees } \\
\text { up working memory to allow you to hold and process more } \\
\text { information at one time. }\end{array}$ \\
\hline Draw attention & Draw Attention & $\begin{array}{l}\text { Drawing attention and emphasizing important information } \\
\text { with visual cues such as color }\end{array}$ \\
\hline
\end{tabular}

Making assessment activities meaningful to higher education stakeholders would facilitate academic communities' understanding of libraries' relevance, value, and impact on the research process and teaching and learning enterprise. ${ }^{25}$ Libraries need to be proactive in mapping their contributions to institutional success. We should take full advantage of the website's broad reach to effectively communicate this alignment by consistently focusing on the external audience, strategic use of design principles, impact narratives/storytelling, and other methods that resonate with the institutional stakeholders. We should also draw upon cognitive science and design theories to guide us in the way we present this information. This 
study explores best practices in library assessment web presence that not only presented assessment content in ways that resonated with higher education goals (student learning and success, faculty productivity, and institutional prestige and reputation), but also used design elements that maximized the communication potential of a website presentation.

\section{Methodology}

In planning for a mini-site on assessment activities, Stony Brook University Libraries researched other library assessment websites. A quick Google search was completed and a few institutions' webpages were reviewed. The variation and lack of information found prompted us to do a more systematic review to discover best practices in what should be communicated through a library assessment webpage and the most effective ways to do so. The sample chosen for this review consisted of 61 (out of 62) AAU institutions, of which Stony Brook University is a member. SBU was excluded from the review because we did not have a website to compare. The three research questions that guided our qualitative inquiry are:

1. Do AAU member institutions have a webpage for library assessment information?

2. What library assessment information can be accessed on library websites of AAU member institutions?

3. For institutions that have a substantial library assessment webpage:

a. Is the information comprehensive?

b. Does it explicitly state a focus on academic library value and impact?

c. Is the information presented in a visually appealing way?

All 61 AAU member websites were initially searched for library assessment information in the summer of 2018 by two library professionals. We cross-checked and calibrated our independent findings with one another in fall 2018 to reach a consensus on the criteria and categorizations. For each institution, we used the following protocol:

\section{Search Protocol}

1. Google "Institution Name" + "Library Assessment"

2. If no information found:

a. Go to institution's library website and review main library page to locate any assessment info

b. If site search available on main library page, search "assessment"

c. Review main library page "About Us" section

Institutions were grouped into the following three categories:

1. No library assessment web presence easily discoverable

2. Some library assessment information present but not substantial

3. Substantial library assessment information located on webpage/webpage 
A criteria checklist grew out of this initial search and analysis and mapped to the recommendations in the $V A L$ and Impact Reports. We then completed a more thorough review of a smaller subset of 13 institutions we considered to have "substantial" library assessment information (see Research Question 2 discussion for definition of "substantial"). For these 13 institutions, we investigated whether the websites were comprehensive, whether they explicitly stated a focus on value/impact of the academic library, and whether the information was presented in a visually appealing way (using cognitive load theory and design thinking concepts). A sample of this checklist is provided in the appendix. We defined "comprehensive" as including the following elements:

- Library value/impact explicitly stated

- Library mission statement

- Library strategic plan

- Information current

- Contact information present

- Survey assessments

- Information literacy/Instruction assessment

- Benchmarking data

- User focus-internal/external audiences

- Supporting faculty research productivity

- Contributing to retention/graduation/academic success measures

- Results of assessment projects outlined and how they inform improvements

\section{Findings}

\section{Research Question 1}

Do AAU member institutions have a webpage for library assessment information?

All 61 member institutions of the AAU (excluding Stony Brook) were searched for library assessment webpages. Through this initial search, we found that 9 institutions did not have a library assessment web presence, ${ }^{26} 39$ had some, though not substantial, assessment information; and 13 had a substantial library assessment webpage or web presence.

\begin{tabular}{|l|l|}
\hline Web Presence & $\begin{array}{l}\text { \# of } \\
\text { Institutions }\end{array}$ \\
\hline No library assessment webpage presence & 9 \\
\hline Some assessment information but not substantial & 39 \\
\hline Substantial library assessment webpage & 13 \\
\hline Total institutions reviewed & 61 \\
\hline
\end{tabular}

\section{Research Question 2}

What library assessment information can be accessed on library webpages of AAU member institutions? 
Through our search and analysis, we found the following to be included on many of the library assessment webpages. This included mission statements/guiding principles, patron surveys (internal and standardized), annual reports, statistics reported to library and higher education associations, benchmarking data, and information literacy/instruction assessment.

\section{Research Question 3}

For institutions that have a substantial library assessment webpage:

a. Is the information comprehensive?

b. Does it explicitly state a focus on academic library value/impact?

c. Is the information presented in a visually appealing way?

We continued to review 13 institutions that we found to have a substantial library assessment presence using the criteria checklist we developed. Based on our definition of comprehensive (as stated above), we found only three institutions met this criterion. Four institutions explicitly stated a focus on academic library value/impact somewhere on their pages. Finally, we found that only two institutions presented their information in a visually appealing way.

\begin{tabular}{|l|l|}
\hline Quality and presentation of web presence & $\begin{array}{l}\text { \# of } \\
\text { Institutions }\end{array}$ \\
\hline Substantial library assessment webpages & 13 \\
\hline Comprehensive assessment information & 3 \\
\hline Explicit statements of focus on academic library value/impact & 4 \\
\hline Information presented in a visually appealing way & 2 \\
\hline
\end{tabular}

The two institutions that demonstrated exemplary webpages for communicating library assessment information are the University of Washington and Iowa State University.

\section{University of Washington}

The main page of the University of Washington library assessment website, www.lib.washington.edu/assessment, lists four icons that direct the reader to different parts of the assessment page. ${ }^{27}$ These icons use dual coding-combining words and pictures-which easily communicates and organizes content. This also simplifies navigation of the site, removing extraneous information which helps to not overwhelm the viewer. However, these icons are only present on the landing page. If these icons were used throughout the assessment webpage and on their fact sheet, it would further help the viewer to more easily identify and navigate the content. 
Figure 1. Dual coding example from the University of Washington Libraries assessment website

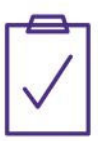

User Feedback Surveys

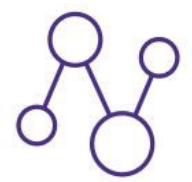

Libraries \& UW Statistics

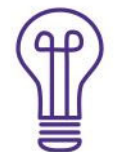

Assessment Projects

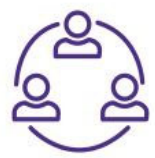

Contact Us

Assessment projects are current and well-outlined, with explanations and links. More common in our review of websites was just a list of links. University of Washington's assessment reports emphasize not only the results of the assessment projects but how these results are used and inform changes and improvements. The links to the strategic plan help the viewer connect assessment projects to the library and institutional goals. There are also links to institutional data collection which show how the library fits within overall institutional assessment.

Contact information is easily accessible, though we found access to the overall page to be difficult. There does not seem to be a way to link to the assessment page from the main library webpage. Their use of the data visualization tool, Tableau, is effective. They include links to statistics with charts and graphs, but they also assume a higher level of library knowledge than might be appropriate for external readers. The assessment information on many of their pages can be overwhelming for a novice or external viewer to manage and understand.

\section{lowa State University}

Iowa State University's library assessment webpage, https://assess.lib.iastate.edu, is easily discoverable and is included under the About Us section of the library's main webpage. ${ }^{28}$ Iowa State University Library is engaging in current comprehensive assessment including surveys, benchmarking data, and information literacy assessment. The website demonstrates a culture of assessment and explicitly states a focus on value and impact. Here is an example from their 2016 Library Student and Postdoc User Survey report describing their survey goal: "To measure the user perceptions of undergraduate students, graduate students, and postdoctoral scholars of the value, impact, and service quality of the services provided by Iowa State University Library." 29

When accessing the main page, the viewer is first introduced to Iowa State University Library's strategy map. This color-coded map breaks down their assessment plan into different perspectives (service, financial, learning, and internal) and is tied to the university's mission on academic excellence. This is a great example of chunking and organizing content effectively. However, these perspectives could have been used throughout the webpage to help the viewer more easily navigate and locate assessment projects based on these different perspectives. The navigation headings on the website (The Plan, Stories, Metrics, Surveys, and Reports) are not intuitive and sometimes reflect an internal perspective rather than presenting information for an external audience. 
Figure 2. Example of effective chunking and organization of content from the Iowa State University Library assessment website.

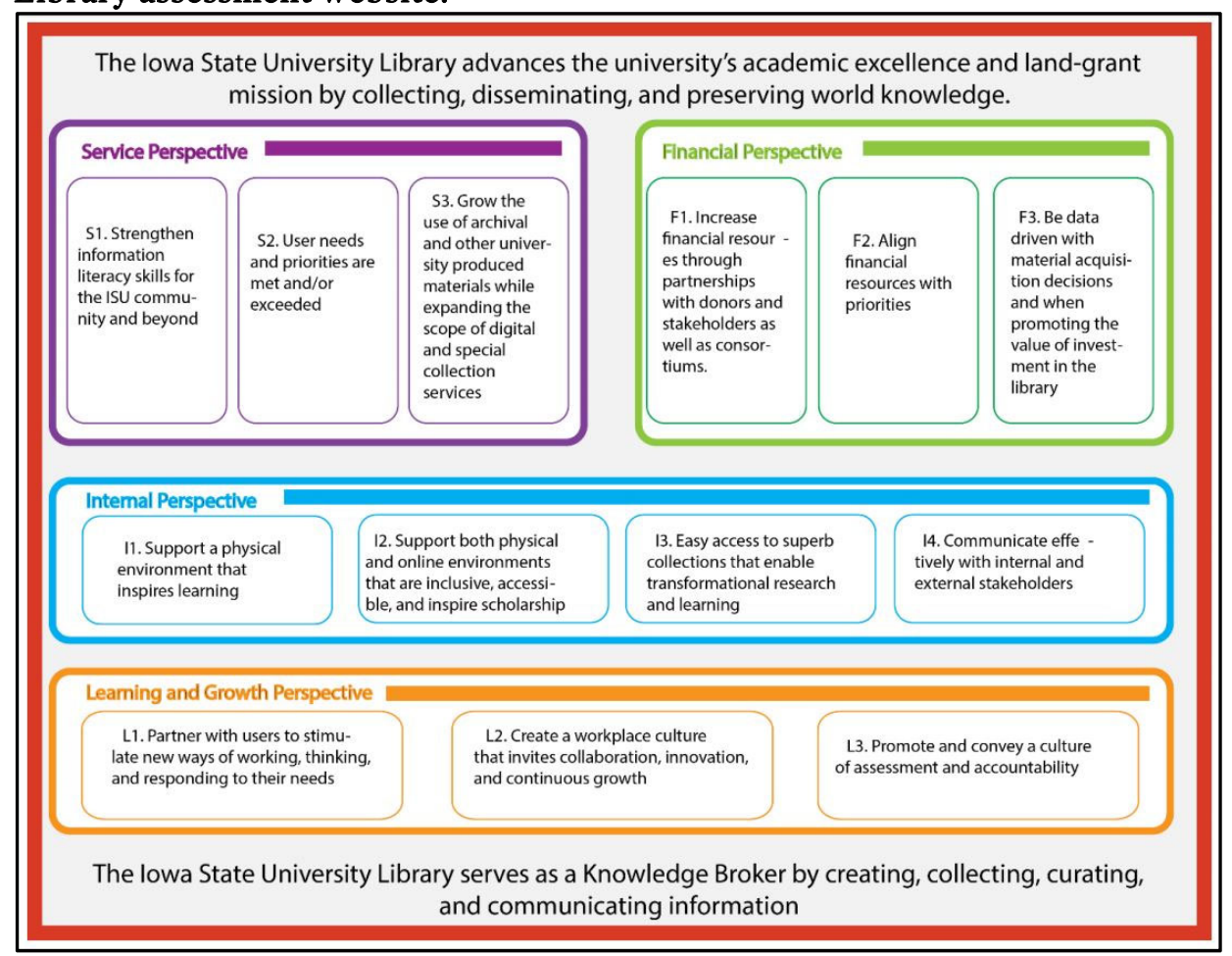

Their use of Tableau assumes some level of knowledge from the viewer but extraneous information has been removed, visuals are appealing, it is not too technical, and the information is concise. The Tableau charts and graphs are interactive so the viewer can engage with the data. In some Tableau charts, they also include a short narrative (or Tableau Story Points) that guides the viewer to interpreting the data. As they stated, "People tend to understand and remember concepts through stories. And they can tell a story with data, just as they can tell a story with text or with film. Tableau Story Points are narratives with data." 30

Iowa State University's Library assessment website demonstrates effective use of judgmental icons in their reports. They use a system of color-coded arrows that quickly communicates to the viewer if they have met, exceeded, or not (yet) met their expectations of goals. This helps to keep the information organized, removes extraneous information, and clearly communicate through the use of graphic icons. 
Figure 3. Example of effective use of judgmental icons from the Iowa State University Library assessment website.

\begin{tabular}{|c|c|c|c|}
\hline \multicolumn{4}{|c|}{ Strategy Map Key Performance Indicator Summary - Service Perspective FY18 } \\
\hline \multirow[t]{4}{*}{$\begin{array}{l}\text { Strategy Map Objective } \\
\text { Strengthen information literacy skills for } \\
\text { the ISU community and beyond }\end{array}$} & $\begin{array}{l}\text { Indicator } \\
\text { Library LibGuide Average } \\
\text { Views }\end{array}$ & $\begin{array}{l}\text { Target } \\
\text { Maintain average views in FY18 } \\
\text { compared to FY17 }\end{array}$ & \multirow[t]{8}{*}{$\begin{array}{l}\text { Exceeding Target } \\
\text { Eeeting Target } \\
\text { M Missed Target }\end{array}$} \\
\hline & Library LibGuide Total Views & $\begin{array}{l}\text { Maintain total views in FY18 } \\
\text { compared to } \mathrm{FY} 17\end{array}$ & \\
\hline & $\begin{array}{l}\text { Library Workshop Average } \\
\text { Attendance }\end{array}$ & $\begin{array}{l}\text { Maintain average attendance in } \\
\text { FY18 compared to } \mathrm{FY} 17\end{array}$ & \\
\hline & $\begin{array}{l}\text { Library Workshop Total } \\
\text { Attendance }\end{array}$ & $\begin{array}{l}\text { Maintain total attendance in FY18 } \\
\text { compared to FY17 }\end{array}$ & \\
\hline \multirow[t]{4}{*}{$\begin{array}{l}\text { User needs and priorities are met and/or } \\
\text { exceeded }\end{array}$} & Improve the User Experience & $\begin{array}{l}\text { Complete at least one action item } \\
\text { identified by user experience } \\
\text { studies }\end{array}$ & \\
\hline & Library Chat Statistics Totals & $\begin{array}{l}\text { Maintain chat totals in FY18 } \\
\text { compared to FY17 }\end{array}$ & \\
\hline & Library Chat Statistics Trends & $\begin{array}{l}\text { Upward trend in the number of } \\
\text { chats from July } 2015 \text { through } \\
\text { June } 2018\end{array}$ & \\
\hline & Library Study Room Bookings & $\begin{array}{l}\text { Increase in the total number of } \\
\text { room bookings in FY18 } \\
\text { compared to FY17 }\end{array}$ & \\
\hline
\end{tabular}

\section{Limitations}

While we found that nine institutions did not have a library assessment web presence, we recognize that they may have a library assessment webpage, just not discoverable based on our search parameters. We also acknowledge that our sample of AAU institutions is a relatively small sample of academic libraries nationwide. We did not review these websites for ADA compliance. We also understand that the lack of a library assessment webpage does not necessarily mean that the institutions do not have a comprehensive and well-structured culture of assessment in their library; it simply means they are not communicating this well through a webpage.

Recommendations for further research include:

- doing a deeper dive in how libraries can use benchmarking data to communicate value, improve and enhance teaching and learning, and communicate with external stakeholders through a website;

- determining whether or how well library strategic plans and assessment activities align with an institution's mission; and

- looking at other samples, such as ARL libraries, other types of academic libraries (community college, 4-year, etc.), or exemplary websites of other types of libraries (public, school, special) for best practices.

\section{Conclusion}

ACRL identified the two most essential areas for research and practice regarding library impact-aligning the library with institutional effectiveness and communicating that alignment in ways that resonate with 
higher education stakeholders. Assessment websites can and should show how the library contributes to student success and faculty research productivity, enhances teaching and learning outcomes, and aligns with the vision and mission of the parent institution. In applying ACRL's criteria to AAU member library assessment websites, we found that the majority of the sample either had no assessment information or inadequately communicated their alignment and impact in higher education terms. While libraries already might be doing excellent assessment work, if they are not communicating these activities effectively on their websites and through impactful narratives, they will not be recognized for the value they bring to their institutions. What this means is that there is great room for improvement for all libraries to better communicate their institutional effectiveness through the web portal.

-Copyright 2019 Kristin Hall and Janet H. Clark

\section{Notes}

1. "Our Members," Association of American Universities, https://www.aau.edu/who-we-are/our-members.

2. Association of College and Research Libraries, Academic Library Impact: Improving Practice and Essential Areas to Research, prepared by Lynn Silipigni Connaway, William Harvey, Vanessa Kitzie, and Stephanie Mikitish (Chicago: Association of College and Research Libraries, 2017), http://www.ala.org/acrl/sites/ala.org.acrl/files/content/publications/whitepapers/academiclib.pdf.

3. Association of College and Research Libraries, Value of Academic Libraries: A Comprehensive Research Review and Report, prepared by Megan Oakleaf (Chicago: Association of College and Research Libraries, 2010), http://www.ala.org/acrl/sites/ala.org.acrl/files/content/issues/value/val_report.pdf.

4. ACRL, Value of Academic Libraries, 42.

5. ACRL, Value of Academic Libraries, 42.

6. ACRL, Value of Academic Libraries, 42.

7. ACRL, Library Impact.

8. ACRL, Library Impact, 46.

9. Heather S. Lewin and Sarah M. Passonneau, "An Analysis of Academic Research Libraries Assessment Data: A Look at Profesional Models and Benchmarking Data," The Journal of Academic Librarianship 38, no. 2 (2012): 91.

10. Institute of Museum and Library Services, "Library Integration in Institutional Learning Analytics," prepared by Megan Oakleaf, November 15, 2018, https://library.educause.edu/ /media/files/library/2018/11/liila.pdf, 7.

11. George A. Miller "The Magical Number Seven, Plus or Minus Two: Some Limits on Our Capacity For Processing Information,” The Psychology Review 63, no. 2 (1956): 81-97.

12. John Sweller, "Cognitive Load During Problem Solving: Effects on Learning," Cognitive Science 12, no. 2 (1988): 257-285.

13. Jennifer J. Little, “Cognitive Load Theory and Library Research Guides," Internet Reference Services Quarterly 15, no. 1 (2010): 53-54.

14. John Sweller, "Element Interactivity and Intrinsic, Extraneous and Germane Cognitive Load," Educational Psychology Review 22, no. 2 (2010): 123-138.

15. Sweller, "Element Interactivity." For a more in-depth review of cognitive load theory see Cognitive Load Theory by John Sweller, Paul Ayres and Slava Kalyuga.

16. Stephanie D. Evergreen, Presenting Data Effectively: Communicating Your Findings for Maximum Impact (Los Angeles: Sage Publications, 2014), 9.

17. Schweppe and Rummer, 286. Judith Schweppe and Ralf Rummer, "Attention, Working Memory, and Long-Term Memory in Multimedia Learning: An Integrated Perspective Based on Process Models of Working Memory," Educational Psychology Review 26, no. 2 (2014): 285-306. 
18. For a more in-depth review of dual coding theory, see Mind and Its Evolution: A Dual Coding Theoretical Approach by Allan Paivio.

19. Evergreen, Presenting Data Effectively, 12.

20. Evergreen, Presenting Data Effectively, 36.

21. Evergreen, Presenting Data Effectively, 39.

22. For more information about reference and judgmental icons, see Presenting Data Effectively by Evergreen.

23. Miller, "The Magical Number Seven."

24. Miller, "The Magical Number Seven."

25. Lewin and Passonneau, "An Analysis," 85-86.

26. While we did not find a library assessment web presence for nine institutions, we recognize that they might exist; they were simply not discoverable based on our search parameters.

27. "Assessment," University of Washington Libraries, accessed June 12, 2018, http://www.lib.washington.edu/assessment/.

28. “Library Assessment,” Iowa State University Library, accessed June 12, 2018, https://assess.lib.iastate.edu/.

29. "2016 Library Student and Postdoc User Survey Report," Iowa State University Library, accessed September 18, 2018.

30. "Library Tableau Stories,” Iowa State University Library, accessed September 18, 2018, https://assess.lib.iastate.edu/stories.

\section{Bibliography}

Association of American Universities. Our Members. Accessed June, 2018. https://www.aau.edu/who-weare/our-members.

Association of College and Research Libraries. The Value of Academic Libraries: A Comprehensive Research Review and Report. Prepared by Megan Oakleaf. Chicago, IL: Association of College and Research Libraries, 2010.

Connaway, Lynn Silipigni, William Harvey, Vanessa Kitzie, and Stephanie Mikitish. Academic Library Impact: Improving Practice and Essential Areas to Research. Chicago: Association of College and Research Libraries, 2017.

Evergreen, Stephanie D. Presenting Data Effectively: Communicating Your Findings for Maximum Impact. Los Angeles: Sage Publications, 2014.

Institute of Museum and Library Services. 2018. "Library Integration in Institutional Learning Analytics." Prepared by Megan Oakleaf. Accessed November, 2018. https://library.educause.edu/ /media/files/library/2018/11/liila.pdf.

Iowa State University Library. "Library Assessment.” Accessed June, 2018. https://assess.lib.iastate.edu/.

Iowa State University Library. “2016 Library Student and Postdoc User Survey Report.” Accessed September, 2018. https://assess.lib.iastate.edu/sites/default/files/Survey\%20Uploads/2016\%20Library\%20Student\%20an d\%20Postdoc\%20User\%20Survey\%20Report\%20-\%20December\%202016\%20-\%20Final\%20(4-517).pdf.

Iowa State University Library. “Library Tableau Stories.” Accessed September, 2018. https://assess.lib.iastate.edu/stories. 
Lewin, Heather S., and Sarah M. Passonneau. "An Analysis of Academic Research Libraries Assessment Data: A Look at Profesional Models and Benchmarking Data." The Journal of Academic Librarianship 38, no 2 (2012): 85-93.

Little, Jennifer J. “Cognitive Load Theory and Library Research Guides.” Internet Reference Services Quarterly 15, no. 1(2010): 53-63.

Miller, George A. "The Magical Number Seven, Plus or Minus Two: Some Limits on Our Capacity For Processing Information.” The Psychology Review 63, no. 2 (1956): 81-97.

Paivio, Allan. Mind and Its Evolution. New York: Psychology Press, 2006.

Schweppe, Judith, and Ralf Rummer. "Attention, Working Memory, and Long-Term Memory in Multimedia Learning: An Integrated Perspective Based on Process Models of Working Memory. " Educational Psychology Review 26, no. 2 (2014): 285-306.

Spector, J. Michael. The Sage Encyclopedia of Educational Technology. Los Angeles: Sage Publications, 2015.

Sweller, John. "Cognitive Load During Problem Solving: Effects on Learning. " Cognitive Science 12, no. 2 (1988): 257-285.

Sweller, John. "Element Interactivity and Intrinsic, Extraneous and Germane Cognitive Load." Educational Psychology Review 22, no. 2 (2010): 123-138.

Sweller, John, Paul Ayres, and Slava Kaluga. Cognitive Load Theory. New York: Springer, 2011.

University of Washington Libraries. “Assessment.” Accessed June, 2018.

http://www.lib.washington.edu/assessment. 
Appendix: Assessment Website Criteria Checklist

Date:

University/College:

Reviewer:

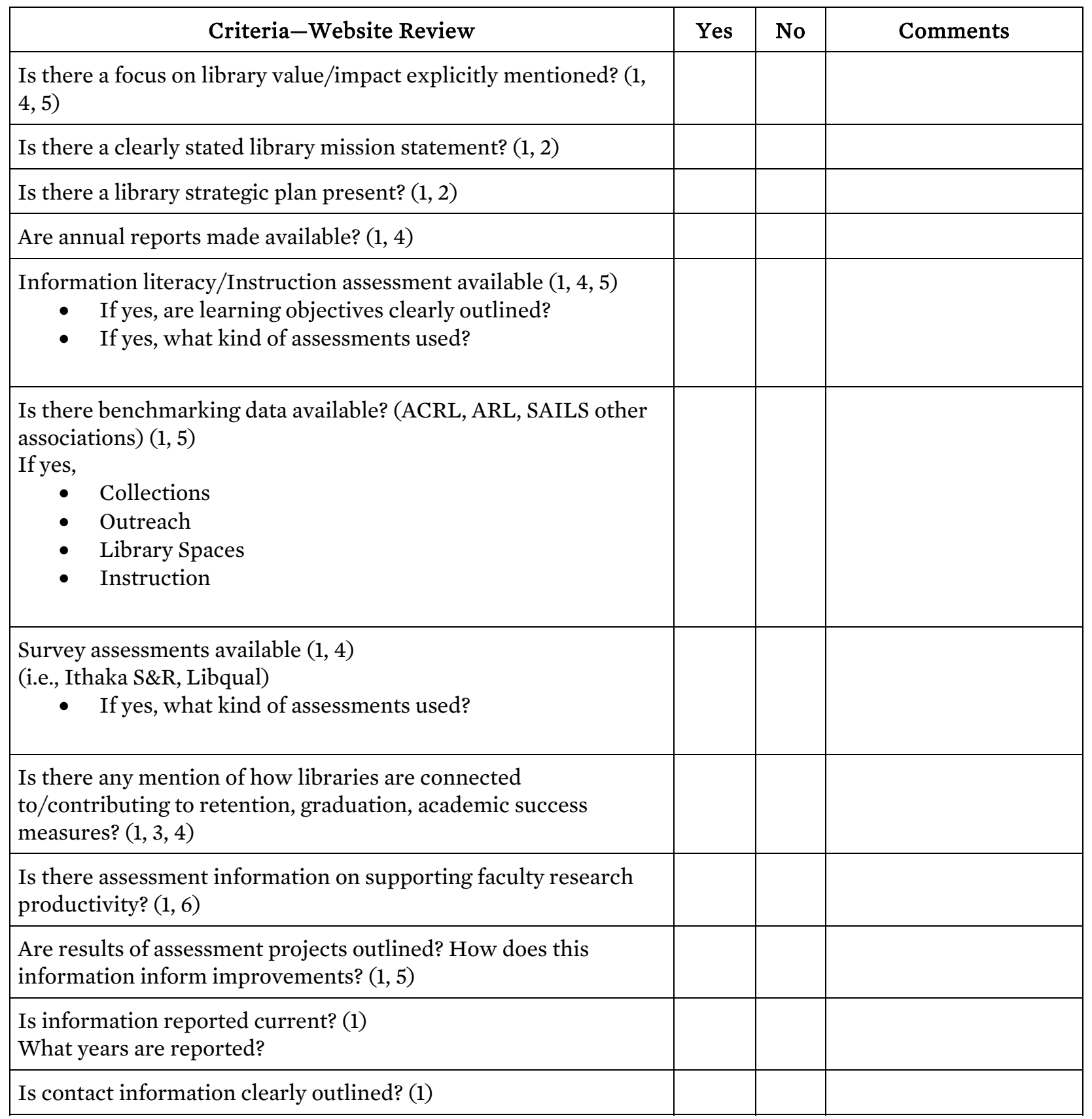




\begin{tabular}{|c|c|}
\hline Criteria-Website Review & Comments \\
\hline $\begin{array}{l}\text { Where is the assessment website/webpage located? (1) } \\
\text { How do you navigate to the page? }\end{array}$ & \\
\hline $\begin{array}{l}\text { What is the main user focus of the website/webpage? (1) How } \\
\text { prevalent is library jargon? }\end{array}$ & $\begin{array}{l}\text { Internal library } \\
\text { External library } \\
\text { Students } \\
\text { Faculty } \\
\text { Administration } \\
\text { Community }\end{array}$ \\
\hline $\begin{array}{l}\text { Design Principles } \\
\text { Dual Coding } \\
\text { Organization } \\
\text { Extraneous information } \\
\text { Chunking } \\
\text { Drawing attention }\end{array}$ & \\
\hline Notes: & \\
\hline
\end{tabular}

